\title{
Clinical analysis of concomitant valve replacement and bipolar radiofrequency ablation in 191 patients
}

\author{
Li Dong, MD, ${ }^{\mathrm{a}}$ Bo Fu, MD, ${ }^{\mathrm{a}}$ Xiao Teng, MD, ${ }^{\mathrm{a}}$ Hong-sheng Yuan, MD, ${ }^{\mathrm{a}}$ Shu-lin Zhao, MD, ${ }^{\mathrm{a}}$ and \\ Li Ren, MD ${ }^{\mathrm{b}}$
}

Objective: The study objective was to evaluate the safety and efficacy of concomitant bipolar radiofrequency ablation and heart valve replacement in patients with rheumatic heart disease and atrial fibrillation.

\begin{abstract}
Methods: A total of 191 patients with rheumatic heart disease and chronic atrial fibrillation underwent valve replacement with concomitant bipolar radiofrequency ablation. There were 78 male and 113 female patients with a mean age of $46.0 \pm 9.1$ years and an atrial fibrillation duration of $43.7 \pm 15.4$ months. Valve replacement surgery included mitral valve replacement in 121 patients, mitral and aortic valve replacement in 59 patients, mitral and tricuspid valve replacement in 8 patients, and triple valve replacement in 3 patients. All patients received oral antiarrhythmic drugs for 3 to 6 months postoperatively. Follow-up electrocardiography and color Doppler echocardiography were performed postoperatively.
\end{abstract}

Results: The mean aortic crossclamping time was $84.0 \pm 25.5$ minutes, and cardiopulmonary bypass time was $139.4 \pm 39.1$ minutes. There was no abnormal bleeding due to bipolar radiofrequency ablation. Three patients $(1.57 \%)$ died of low cardiac output syndrome in hospital at 2, 3, and 5 days after surgery. Major perioperative complications include reoperation for bleeding $(n=1)$, reoperation for wound infection $(n=1)$, intra-aortic balloon pump placement $(\mathrm{n}=2)$, and renal failure $(\mathrm{n}=2)$. All other patients were discharged without complications. The mean follow-up time was $17.4 \pm 11.8$ months with a follow-up rate of $95.3 \%$. There were no cases of late death, complete atrioventricular block, or anticoagulation-induced complications. Of 158 patients who were followed up for 1 year, sinus rhythm was maintained in $125(79.11 \%)$.

Conclusions: Concomitant bipolar radiofrequency ablation is an effective and safe technique for treating atrial fibrillation in patients with rheumatic heart disease undergoing valve replacement, with promising follow-up results. (J Thorac Cardiovasc Surg 2013;145:1013-7)

Atrial fibrillation (AF) is the most common dysrhythmia encountered in clinical practice, ${ }^{1}$ with an overall prevalence of $0.77 \%$ in China and a prevalence of $45 \%$ to $60 \%$ among those with rheumatic heart disease. ${ }^{2} \mathrm{AF}$ has high morbidity and mortality rates, including complications such as stroke and heart failure, which affect patient quality of life. Surgery is the most effective treatment option for $\mathrm{AF}^{3}$ The Cox Maze III procedure is regarded as the gold standard for the treatment of $\mathrm{AF}^{4,5}$ but it is complicated, timeconsuming, and traumatic, which limit its clinical usefulness. Many improved Maze procedures have therefore been proposed, among which bipolar radiofrequency ablation (BRFA) is currently of interest. In the current study,

From the Departments of Cardiac Surgery ${ }^{\mathrm{a}}$ and Oncology, ${ }^{\mathrm{b}}$ West China Hospital, Sichuan University, Chengdu, China.

Disclosures: Authors have nothing to disclose with regard to commercial support. B.F. is the co-first author

Received for publication Dec 28, 2011; revisions received March 26, 2012; accepted for publication May 7, 2012; available ahead of print June 7, 2012.

Address for reprints: Li Ren, MD, Department of Oncology, West China Hospital, Sichuan University, No 37, Guoxue Alley, Chengdu 610041, China (E-mail: renlihx@163.com or doctorfu510@163.com).

0022-5223/\$36.00

Crown Copyright (C) 2013 Published by Elsevier Inc. on behalf of The American Association for Thoracic Surgery

doi:10.1016/j.jtcvs.2012.05.009 our prospective data were reviewed to evaluate the predictors in 191 consecutive patients who underwent BRFA with valve replacement from January 2009 to June $2011 .^{2}$

\section{MATERIALS AND METHODS \\ Clinical Data}

The present study included 78 male and 113 female patients with a mean age ( \pm standard deviation) of $46.0 \pm 9.1$ years (range, 20-66 years). AF was defined as paroxysmal, persistent, or long-standing persistent per recent guidelines. ${ }^{6}$ The median duration of AF was $43.7 \pm 15.4$ months (6-120 months). All of the patients had persistent or long-standing persistent AF. There was no history of embolism in any of the patients. Major comorbidities include coronary heart disease $(\mathrm{n}=0)$, chronic obstructive pulmonary disease $(n=5)$, and diabetes $(n=2)$. Valvular diseases included rheumatic valve disease in 175 patients and degenerative valve diseases in 16 patients. According to the New York Heart Association functional classification system, 48 patients were graded as class II, 131 patients were graded as class III, and 12 patients were graded as class IV. Preoperative color Doppler echocardiography demonstrated a mean left atrial diameter of 36 to $109 \mathrm{~mm}(56.7 \pm 11.3 \mathrm{~mm})$, left ventricular end-diastolic diameter of 33 to $80 \mathrm{~mm}(49.8 \pm 8.1 \mathrm{~mm})$, left ventricular ejection fraction of $35 \%$ to $72 \%(57.3 \% \pm 6.6 \%)$, and left atrial thrombus in 41 patients. Preoperative standard 12-lead electrocardiography (ECG) showed AF in all patients.

Surgery included mitral valve replacement in 121 patients, double mitral and aortic valve replacement in 59 patients, double mitral and tricuspid valve replacement in 8 patients, and triple valve replacement in 3 patients. Imported St Jude Medical, Inc (St Paul, Minn ) bileaflet mechanical valves 


\section{Abbreviations and Acronyms \\ $\mathrm{AF}=$ atrial fibrillation \\ BRFA $=$ bipolar radiofrequency ablation \\ $\mathrm{ECG}=$ electrocardiography}

were used in 179 patients, and biological prosthetic valves were used in 12 patients. Concomitant tricuspid valvuloplasty, left atrial thrombectomy, and left atrial plication were performed in 69, 59, and 13 patients, respectively.

Late recurrence was defined as any episode of AF, atrial flutter, or atrial tachycardia that lasted more than 30 seconds. Patients were only considered to be a success if they were not taking antiarrhythmic drugs and were free of atrial tachyarrhythmias. ${ }^{7}$

The medical ethical committee of West China Hospital approved the study. Informed consent and permission for release of information were obtained from each participant.

\section{Surgical Procedures}

All surgery was performed under general anesthesia with moderate hypothermia and moderate hemodilution. An AtriCure Bipolar System (isolators and GlidePath tape; AtriCure Inc, Cincinnati, Ohio) was used for BRFA, according to the following protocol. All lesions were performed with the BRFA device. After induction of general anesthesia, an esophageal echocardiography probe was placed to evaluate valve pathology, cardiac function, and left atrial thrombus. The patient was then heparinized. If there was no left atrial thrombus, the right pulmonary vein was isolated and a circular ablation line was performed on the beating heart before aortic crossclamping. After aortic crossclamping, the right pulmonary vein and left atrial appendage were isolated and the ligament of Marshall was cut. ${ }^{8}$ The left atrium was entered via the right atrium through the interatrial septum. Ablation lines were created between the left atrial appendage and the left superior pulmonary vein, between the bilateral superior and inferior pulmonary veins, between the right inferior pulmonary vein and the left superior pulmonary vein, and between the posterior leaflets of the mitral valve. If there was left atrial thrombus, aortic crossclamping was performed first followed by atrial thrombectomy with care to avoid coronary artery damage, before isolation of the pulmonary vein and left atrium. The left atrial appendage was then sutured closed from the internal aspect, followed by valve replacement surgery. The interatrial septum was sutured closed, and an ablation line was created in the wall of the right atrium from the right atrial incision to the inferior vena cava and the anterior leaflet of the tricuspid valve (Figure 1). ${ }^{9}$ Ablation lines should all be ablated at least 4 times,

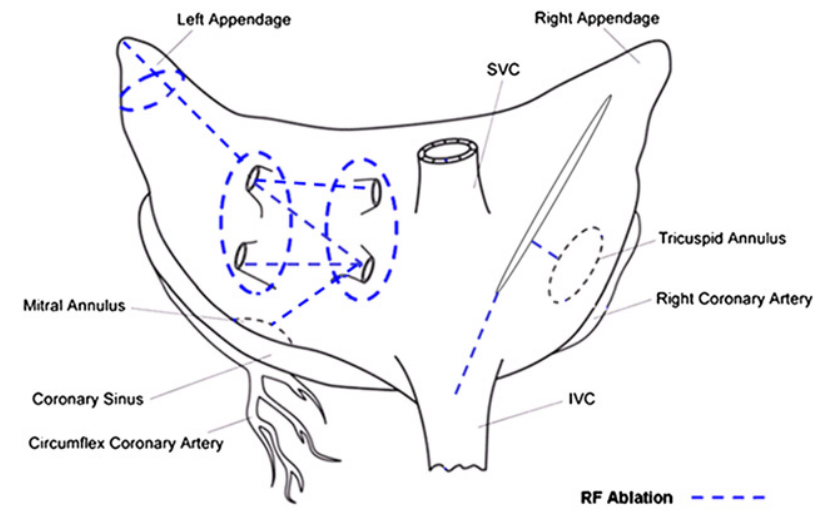

FIGURE 1. Cox maze lesion set made with IBRF device. SVC, Superior vena cava; $I V C$, inferior vena cava. and the circular ablation line around the pulmonary veins should be ablated at least 5 times. Valve function was assessed by transesophageal echocardiography, and temporary cardiac pacing wires were placed.

\section{Postoperative Care}

All patients received a postoperative amiodarone infusion $(0.5-1.5 \mathrm{mg} /$ $\mathrm{kg} / \mathrm{h}$ ) to maintain the heart rate at 60 to 140 beats/min after weaning from cardiopulmonary bypass. After the patients were discharged from the intensive care unit, the drug was administered orally, starting at $200 \mathrm{mg} / \mathrm{d}$ once or twice daily, for 3 to 6 months and then adjusted according to the heart rate, because early postoperative arrhythmias may be caused by mechanisms other than persistent or long-standing persistent AF. If patients were in sinus rhythm at 3 months, the antiarrhythmic drugs were discontinued $(n=148)$. If patients failed to maintain sinus rhythm at 3 to 6 months, we resumed antiarrhythmic treatment and attempted electrical cardioversion if required $(\mathrm{n}=34) .{ }^{10}$ For the purpose of this analysis, we defined antiarrhythmic drugs as class I or III. Beta-blockers or calcium channel blockers were not considered to be antiarrhythmic drugs. ${ }^{7}$ Warfarin was administered orally for 48 hours after surgery to maintain the international normalized ratio at 1.5 to $2.0 .^{11}$

\section{Follow-up}

All data were obtained for each patient during the postoperative period. The clinical examination and a 12-lead ECG were obtained at each visit, and an echocardiography analysis was performed after 3,6 , and 12 months. In all patients, oral anticoagulation was maintained and discontinued in the patients undergoing valve repair or replacement with bioprostheses who were in sinus rhythm within 3 months postoperatively. ${ }^{12}$

\section{Statistic Analysis}

Statistical analysis was performed using SPSS software version 18 (SPSS Inc, Chicago, Ill). All data are expressed as the mean \pm standard deviation. Quantitative data were compared using the Student $t$ test. Multiple logistic regression analysis with forward selection, backward elimination, and stepwise regression methods was used to analyze relationships between variables and surgical outcomes. Levels of statistical significance were set at significance level of entry $=0.30$ and significance level of staying $=0.05$.

\section{RESULTS}

Aortic crossclamping time was $81.3 \pm 31.2$ minutes (49155 minutes), and cardiopulmonary bypass time was $139.4 \pm 39.1$ minutes (61-224 minutes). The additional aortic crossclamping time required for the radiofrequency ablation was $21.9 \pm 3.7$ minutes (13-32 minutes). Three patients died of low cardiac output syndrome at 2, 3, and 5 days after surgery. Major perioperative complications include reoperation for bleeding $(\mathrm{n}=1)$, reoperation for wound infection $(\mathrm{n}=1)$, intra-aortic balloon pump placement $(\mathrm{n}=2)$, and renal failure $(\mathrm{n}=2)$. All other patients were discharged without complications such as endocarditis, pneumonia, stroke, prolonged ventilation, and permanent pacemaker. Follow-up was successfully undertaken in 182 patients $(95.3 \%)$ with a follow-up time of 2 to 29 months (17.4 \pm 11.8 months). Of 158 patients who were followed up for 1 year after surgery, $125(79.11 \%)$ had normal sinus rhythm confirmed by ECG and echocardiography (atrial A wave) (Table 1). There were no cases of late death, complete atrioventricular block, or anticoagulation-induced complications, such as hemorrhage and thromboembolism 
TABLE 1. Postoperative cardiac rhythm of 182 patients

\begin{tabular}{lrrr}
\hline \multicolumn{1}{c}{ Time } & Sinus rhythm & Nodal rhythm & $\begin{array}{c}\text { AF/atrial flutter/atrial } \\
\text { tachycardia }\end{array}$ \\
\hline Day of surgery & $82.97 \%(151 / 182)$ & $4.95 \%(9 / 182)$ & $12.09 \%(22 / 182)$ \\
Day of discharge & $72.53 \%(132 / 182)$ & $0(0 / 182)$ & $13.74 \%(25 / 182)$ \\
3 mo after surgery & $81.32 \%(148 / 182)$ & $0(0 / 182)$ & $18.68 \%(34 / 182)$ \\
6 mo after surgery & $80.22 \%(146 / 182)$ & $0(0 / 182)$ & $19.78 \%(36 / 182)$ \\
1 y after surgery & $79.11 \%(125 / 158)$ & $4.43 \%(7 / 158)$ & $16.45 \%(26 / 158)$ \\
\hline
\end{tabular}

$A F$, Atrial fibrillation.

during the follow-up period. Echocardiography showed reduced left atrial and ventricular diameters and increased left ventricular ejection fraction compared with preoperative values. The results are shown in Table 2.

Multiple logistic regression analysis was used to analyze the effects of age, duration of AF, preoperative atrial and ventricular diameters, left ventricular ejection fraction, aortic crossclamping time, cardiopulmonary bypass time, and BRFA time on surgical outcomes. ${ }^{13,14}$ Our results showed significant associations between the duration of $\mathrm{AF}$ and preoperative left atrial diameter and surgical outcome $(P<.01)$. No significant associations were found between other variables and surgical outcome (Table 3 ).

\section{DISCUSSION}

$\mathrm{AF}$ is the most common sustained arrhythmia encountered in clinical practice. This arrhythmia results in irregular atrial electrical activity and loss of atrial contraction. AF may be caused by multiple mechanisms. Most ectopic excitatory foci are located in the pulmonary veins, particularly in the superior pulmonary veins. AF results from the combination of multiple wavelets induced by ectopic atrial excitation and reentry pathways. AF has 3 main consequences: (1) patient anxiety due to irregular palpitations; (2) loss of coordinated atrioventricular contraction resulting in a $30 \%$ reduction in cardiac output, and eventual congestive heart failure; and (3) blood stasis in the left atrium, which may result in thrombosis and embolism. Because the mortality rate in patients with AF is doubled compared with patients without AF, treatment is important. ${ }^{6}$ Surgery is the most effective treatment for AF, with the Cox Maze III procedure considered the gold standard with a $99 \%$ success rate. During the Cox Maze III procedure, multiple linear

TABLE 2. Atrial and ventricular diameters before and after surgery

\begin{tabular}{lcc}
\hline \multicolumn{1}{c}{ Measurement } & $\begin{array}{c}\text { Before surgery } \\
(\mathbf{m m})\end{array}$ & $\begin{array}{c}\text { After surgery } \\
(\mathbf{m m})\end{array}$ \\
\hline Left atrial diameter & $56.7 \pm 11.4$ & $45.8 \pm 8.4^{*}$ \\
Left ventricular diameter & $49.9 \pm 8.2$ & $45.8 \pm 5.6^{*}$ \\
Left ventricular ejection fraction & $57.3 \pm 6.7$ & $59.4 \pm 6.0^{*}$ \\
\hline *Student $t$ test for paired quantitative data. $P<.01$, mean \pm standard deviation, \\
$\mathrm{n}=158$.
\end{tabular}

cuts are made to isolate the atrium from the pulmonary veins and reduce connections between atrial tissues, so that the reentry of multiple wavelets is blocked and the heart can revert to normal sinus rhythm and regular atrioventricular contraction. However, the Cox Maze III procedure is a complicated and time-consuming operation causing significant trauma and complications,${ }^{15}$ including a high rate of postoperative bleeding and sick sinus syndrome, which limits its usefulness. Recent techniques have combined the Maze operation with other procedures, including radiofrequency ablation, microwave ablation, cryoablation, and laser ablation, among which radiofrequency ablation is the most commonly used. ${ }^{16}$

Radiofrequency ablation uses the hyperthermic effects of radiofrequency current and its ability to penetrate tissues to induce transmural myocardial injury by coagulation necrosis to block the reentry loops that cause and maintain AF. The radiofrequency electrodes can be unipolar or bipolar. The unipolar electrode is easier to move around but requires a longer time for coagulation and is more difficult to target precisely. It is more difficult to judge if transmural ablation is complete with a unilateral electrode, and it is easy to damage adjacent tissues (especially the esophagus and pulmonary veins). BRFA is gradually being introduced into clinical practice. The AtriCure bipolar radiofrequency device used in the present study is a clamp that places the negative and positive electrodes on either side of the targeted tissues to precisely focus the energy. The device has an intelligent and fast-acting feedback system and creates a tidy ablation line with clear boundaries, which ensures good penetration and avoids indirect damage to surrounding tissues. ${ }^{17}$

Of the 182 patients who were followed up, $79.11 \%$ were maintaining normal sinus rhythm at 1 year postoperatively as verified by ECG and color Doppler echocardiography. Furthermore, there was a significant reduction in left atrial diameter and recovery of left atrial contraction in patients who maintained sinus rhythm postoperatively, which is consistent with previous reports. ${ }^{18-20}$ Considering the results of the present study, we propose the following: (1) AF ablation lesions should be closely interconnected, particularly in areas that may have multiple accessory pathways, such as the atrioventricular ring and the openings of the large vessels. This will increase the success rate of blocking 
TABLE 3. Results of logistic regression analysis showing associations between duration of atrial fibrillation and preoperative left atrial diameter and surgical outcome

\begin{tabular}{lcccccc}
\hline \multicolumn{1}{c}{ Variable } & Standard error & Regression coefficient & Odds ratio & Wald chi-square & $\boldsymbol{P}$ & $\mathbf{9 5} \%$ CI \\
\hline AF time (wk) & 0.0217 & -0.0846 & 0.919 & 15.18 & $<.001$ & $0.881-0.959$ \\
Preoperative left atrial diameter & 0.0312 & -0.1472 & 0.863 & 22.24 & $<.001$ & $0.812-0.918$ \\
\hline
\end{tabular}

$C I$, Confidence interval; $A F$, atrial fibrillation.

accessory pathways that can easily cause reentry loops. ${ }^{21}$ (2) Maze procedure ablation must be transmural, otherwise the residual myocardial tissue can continue to conduct electrical activity and form or maintain reentry loops. ${ }^{22}$ Ablation lines should all be ablated at least 4 times, and the circular ablation line around the pulmonary veins should be ablated at least 5 times. Careful operation will not increase the risk of bleeding. (3) In patients with left atrial enlargement, the number of ablation lines should be increased, or the atrial volume should be reduced by left atrial plication $(n=7)$, to reduce the area of each section of atrial myocardium and decrease the likelihood of reentry loops. (4) The left atrial appendage should be closed to avoid thrombosis $(\mathrm{n}=84)$, which also helps to reduce the left atrial volume. Surgical closure of the left atrial appendage includes ligation, suture of the opening from the internal aspect, or resection and suturing. Our experience indicates that suturing of the opening from the internal aspect is adequate and safe. (5) Maze procedure ablation of the right atrium should be performed before crossclamping of the ascending aorta or after release of the aortic clamp at the end of surgery to reduce aortic crossclamping time and cardiac ischemia time. (6) Concomitant correction of tricuspid disease should be performed in cases with tricuspid regurgitation of at least mild severity, tricuspid dilatation, or a poorly developed or small anterior valve leaflet. AF can aggravate tricuspid regurgitation and thereby increase the incidence of heart failure and thrombosis, ${ }^{23}$ and correction of tricuspid disease (tricuspid valve replacement $=11$, tricuspid valvuloplasty $=69$ ) increases the success rate of BRFA and assists the recovery of cardiac function. (7) Partial pericardial adhesion $(\mathrm{n}=2)$ should not be a contradiction to radiofrequency ablation. Because concomitant radiofrequency ablation and valve replacement surgery may be a unique chance to radically treat AF, pericardial adhesions should be divided if the patient's condition permits. (8) Adjuvant antiarrhythmic treatment, such as amiodarone (Cordarone; Sanofi-Aventis, Paris, France) administration, is important. Although recurrence of AF early after surgery may be due to failure of tissue ablation, it may also be due to postoperative myocardial edema and inflammatory

TABLE 4. Duration of atrial fibrillation versus left atrial diameter

\begin{tabular}{lccc}
\hline Duration of AF & LA 30-60 $\mathbf{~ m m}$ & LA $\mathbf{6 0 - 8 0} \mathbf{~ m m}$ & LA $>\mathbf{8 0 ~} \mathbf{~ m m}$ \\
\hline $6-12 \mathrm{mo}$ & 22 & 4 & 0 \\
$>12 \mathrm{mo}$ & 98 & 60 & 7 \\
\hline
\end{tabular}

$A F$, Atrial fibrillation; $L A$, left atrium. reactions, which may cause reduction in the atrial refractory period for 3 to 6 months.

The results of the present study indicate that the left atrial diameter and the duration of AF may be important factors affecting the recovery and maintenance of sinus rhythm after radiofrequency ablation. ${ }^{24,25}$ Seven patients had a left atrial diameter of more than $80 \mathrm{~mm}$ before surgery, of whom 2 maintained sinus rhythm and 5 had recurrence of AF within 1 month after surgery. This may be because the ablation-induced damage around the pulmonary veins accounts for a smaller proportion of atrial myocardial tissue in patients with a bigger left atrium, thereby decreasing the likelihood of blocking the reentry loops. The "AF begets AF" phenomenon, which describes the tendency of AF to reinitiate itself and become repetitive or continuous, means that the longer the duration of AF, the more stable it becomes and the more difficult it becomes to revert to sinus rhythm. Our observations indicate that it is easier to maintain sinus rhythm after radiofrequency ablation in patients with a left atrial diameter less than $60 \mathrm{~mm}$ and a duration of AF less than 36 months. A total of 120 patients $(\mathrm{n}=116 / 120,96.67 \%)$ had a left atrial dimension less than $60 \mathrm{~mm}$. A total of 64 patients $(\mathrm{n}=61 / 63,96.83 \%)$ had a duration of AF less than 36 months (Table 4). Age is usually considered an important factor affecting the recurrence rate of $\mathrm{AF}$, but the present study did not find any correlation between age and the effectiveness of radiofrequency ablation, with all 3 patients aged more than 60 years reverting to sinus rhythm after surgery.

Three patients died of low cardiac output syndrome at 2,3, and 5 days after surgery, respectively. These 3 patients had poor cardiac function before surgery, were aged more than 55 years, and had longer aortic crossclamping and cardiopulmonary bypass times than other patients. This suggests that there should be strict indications for valve replacement surgery with concomitant radiofrequency ablation to avoid extra myocardial damage due to the prolongation of aortic crossclamping and cardiopulmonary bypass times needed to perform radiofrequency ablation, and to avoid subsequent severely low cardiac output and related complications.

\section{Study Limitations}

The patients did not undergo rigorous follow-up by present standards. Few of the patients had any monitoring more than 12-lead ECG and electrocardiogram to document their rhythm. Furthermore, the long-term results of BRFA still require further study. 


\section{CONCLUSIONS}

Because of the multiple adverse consequences of AF, recovery of sinus rhythm and atrial contraction has significant effects on the improvement of hemodynamics, cardiac function, and quality of life. When performed concomitantly with valve replacement surgery, BRFA does not significantly prolong aortic crossclamping or cardiopulmonary bypass times and has minor effects on the degree of myocardial ischemia and trauma, but it has a good short-term success rate. In addition, BRFA is simple and safe, and therefore deserves to be promoted.

\section{References}

1. Falk RH. Atrial fibrillation. N Engl J Med. 2001;344:1067-78.

2. Zhou ZQ, Hu DY, Chen J, Zhang RH, Li KB, Zhao XL. An epidemiological survey of atrial fibrillation in China. Chin J Inter Med. 2004;43:491-4.

3. Gillinow AM, Wolf RK. Surgical ablation of atrial fibrillation. Prog Cardiovasc Dis. 2005;48:169-77.

4. Ad N, Henry L, Hunt S, Holmes SD. Do we increase the operative risk by adding the Cox Maze III procedure to aortic valve replacement and coronary artery bypass surgery? J Thorac Cardiovasc Surg. 2012;143:936-44.

5. Cox JL, Schuessler RB, D'Agostino HJ Jr, Stone CM, Chang BC, Cain ME, et al. The surgical treatment of atrial fibrillation. III. Development of a definitive surgical procedure. J Thorac Cardiovasc Surg. 1991;101:569-83.

6. Calkins H, Brugada J, Packer DL, Cappato R, Chen SA, Crijns HJ, et al. HRS/ EHRA/ECAS expert consensus statement on catheter and surgical ablation of atrial fibrillation: recommendations for personnel, policy, procedures and follow-up a report of the Heart Rhythm Society (HRS) Task Force on Catheter and Surgical Ablation of Atrial Fibrillation. Europace. 2007;9:335-79.

7. Damiano RJ Jr, Schwartz FH, Bailey MS, Maniar HS, Munfakh NA, Moon MR, et al. The Cox maze IV procedure: predictors of late recurrence. $J$ Thorac Cardiovasc Surg. 2011;141:113-21.

8. Kim DT, Lai AC, Hwang C, Fan LT, Karagueuzian HS, Chen PS, et al. The ligament of Marshall: a structural analysis in human hearts with implications for atrial arrhythmias. J Am Coll Cardiol. 2000;36:1324-7.

9. Voeller RK, Zierer A, Lall SC, Sakamoto S, Chang NL, Schuessler RB, et al. The effects of the Cox maze procedure on atrial function. J Thorac Cardiovasc Surg. 2008; 136:1257-64.

10. Ad N, Barnett S, Lefrak EA, Korach A, Pollak A, Gilon D, et al. Impact of followup on the success rate of the cryosurgical maze procedure in patients with rheumatic heart disease and enlarged atria. J Thorac Cardiovasc Surg. 2006;131: 1073-9.
11. Dong L, Shi YK, Tian ZP, Ma JY, Wang X, Yi J. Low intensity anticoagulation therapy after mechanical valve replacement. Chin J Surg. 2003;41:250-2.

12. Lee SH, Kim JB, Cho WC, Chung CH, Jung SH, Choo SJ, et al. The influence of age on atrial fibrillation recurrence after the maze procedure in patients with giant left atrium. J Thorac Cardiovasc Surg. 2011;141:1015-9.

13. Voeller RK, Bailey MS, Zierer A, Lall SC, Sakamoto S, Lawton KJ, et al. Isolating the entire posterior left atrium improves surgical outcomes after the Cox maze procedure. J Thorac Cardiovasc Surg. 2008;135:870-7.

14. Kim JB, Yun TJ, Chung CH, Choo SJ, Song H, Lee JW. Long-term outcome of modified maze procedure combined with mitral valve surgery: analysis of outcomes according to type of mitral valve surgery. J Thorac Cardiovasc Surg. 2010;139:111-7

15. Cox JL, Ad N, Palazzo T, Suyderhoud JP, DeGroot KW, Pirovic EA, et al. Curren status of the maze procedure for the treatment of atrial fibrillation. Semin Thorac Cardiovasc Surg. 2000;12:15-9.

16. Gillinov AM, Saltman AE. Ablation of atrial fibrillation with concomitant cardiac surgery. Semin Thorac Cardiovasc Surg. 2007;19:25-32.

17. Bugge E, Nicholson IA, Thomas SP. Comparison of bipolar and unipolar radiofrequency ablation in an in vivo experimental model. Eur J Cardiothorac Surg. 2005;28:76-80.

18. Geidel S, Ostermeyer J, Lass M, Betzolda M, Duonga A, Jensen F, et al. Three years experience with monopolar and bipolar radiofrequency ablation surgery in patients with permanent atrial fibrillation. Eur J Cardiothorac Surg. 2005; 27:243-9.

19. Tekumit H, Uzun K, Cenal AR, Tataroglu C, Polat A, Akinci E. Midterm results of left atrial bipolar radiofrequency ablation combined with a mitral valve procedure in persistent atrial fibrillation. Cardiovasc J Afr. 2010;21: 137-41.

20. Sie HT, Beukema WP, Elvant A, Misier AR. Long-term results of irrigated radiofrequency modified maze procedure in 200 patients with concomitant cardiac surgery: six years experience. Ann Thorac Surg. 2004;77:512-7.

21. Sie HT, Beukema WP, Misier AR, Elvan A, Ennema J, Haalebos M, et al Radiofrequency modified maze in patients with atrial fibrillation undergoing concomitant cardiac surgery. J Thorac Cardiovasc Surg. 2001;122: 249-56

22. Avitall B, Urbonas A, Urboniene D, Rozmus G, Helmsr R. Linear lesions provide protection from atrial fibrillation induction with rapid atrial pacing. J Cardiovasc Electrophysiol. 2002;13:455-62.

23. Cox JL. Intraoperative options for treating atrial fibrillation associated with mitral valve disease. J Thorac Cardiovasc Surg. 2001;122:212-5.

24. Hoemero F, Rodriquez I, Bueno M, Buendia J, Dalmau MJ, Canovas S, et al. Surgery ablation of permanent atrial fibrillation by means of maze radiofrequency: mid-term results. J Card Surg. 2004;19:383-8.

25. Gaynor SL, Schuessler RB, Bailey MS, Ishii Y, Boineau JP, Gleva MJ, et al. Surgical treatment of atrial fibrillation: predictors of late recurrence. J Thorac Cardiovasc Surg. 2005;129:104-11. 